\title{
THREE CASES OF UNILATERAL PIGMENTARY DEGENERATION*
}

\author{
BY \\ HELGA KOLB AND NICHOLAS R. GALLOWAY \\ Department of Experimental Ophthalmology, Institute of Ophthalmology, London
}

UNILATERAL retinitis pigmentosa has been reported on numerous occasions, but there is still some doubt about its existence as a clinical entity and its relationship to the bilateral form. The Table gives a brief summary of the principal cases recorded in the literature so far.

TABLE

PRINCIPAL CASES OF UNILATERAL RETINITIS PIGMENTOSA RECORDED IN THE LITERATURE, 1865-1962

\begin{tabular}{|c|c|c|c|c|}
\hline Date & Authors & $\begin{array}{l}\text { No. } \\
\text { of } \\
\text { Cases }\end{array}$ & Comments & $\begin{array}{l}\text { Duration of } \\
\text { Observation } \\
\quad \text { (yrs) }\end{array}$ \\
\hline $\begin{array}{l}1865 \\
1870 \\
1873 \\
1882 \\
1890 \\
1907 \\
1915-16 \\
1924 \\
1926 \\
1926 \\
1931 \\
1939 \\
1940 \\
1950 \\
1952 \\
1957 \\
1959 \\
1959 \\
1960 \\
1961 \\
1962\end{array}$ & $\begin{array}{l}\text { Pedraglia } \\
\text { de Wecker } \\
\text { Baumeister } \\
\text { Derigs } \\
\text { Günsburg } \\
\text { Nettleship } \\
\text { Leber } \\
\text { Hine } \\
\text { Rossi } \\
\text { Shoji } \\
\text { Beigelman } \\
\text { Agatston } \\
\text { Löwegren (see Dreisler, 1948) } \\
\text { Dreisler } \\
\text { Maeder and Muller } \\
\text { François and Verriest } \\
\text { Frohmann } \\
\text { Krill and Iser } \\
\text { Dieterle and Avanza } \\
\text { Fronimopoulos, Cofinas, and Lambrou } \\
\text { Mehlmack } \\
\text { Küper, Müller-Limmroth, and Dieckhues } \\
\text { Mehra }\end{array}$ & $\begin{array}{l}1 \\
1 \\
1 \\
1 \\
1 \\
1 \\
1 \\
1 \\
1 \\
1 \\
1 \\
2 \\
1 \\
1 \\
1 \\
1 \\
1 \\
1 \\
3 \\
1 \\
2 \\
2 \\
1\end{array}$ & $\begin{array}{l}\text { ERG changes } \\
\text { With glaucoma } \\
\text { ERG and bilateral glaucoma } \\
\text { ERG changes }\end{array}$ & $\begin{array}{r}2 \\
21\end{array}$ \\
\hline
\end{tabular}

In the electrodiagnostic clinic at the Institute of Ophthalmology we have had the opportunity of examining a large number of pigmentary degenerations and these have included four suspected cases of unilateral retinitis pigmentosa, as well as 65 cases of the bilateral disease. Three of the unilateral cases were thought to be worth recording. Detailed investigation of the fourth patient was not possible.

The three cases to be discussed are of interest because both electroretinograms and electro-oculograms have been performed in addition to other tests. Case 1 is noteworthy because the eye is also affected by closed-angle glaucoma. 


\section{Methods}

Electro-oculography (EOG)

The principle of this test is to measure the changes in the standing potential of the eye under different conditions of illumination. Electrodes are placed on the skin on either side of the eyes and the potentials evoked by regular eye movements are amplified and displayed on a Mingograph recording machine.

This potential is thought to arise across the pigment epithelium of the retina and thus polarize the whole of the eyeball along the optic axis. Increase of retinal illumination causes a large increase in the size of the potential and the ratio between the size of the potential in the dark to that in the light expressed as light peak dark trough $\times 100$ has been evaluated for normal subjects by Arden and Barrada (1962). The variation of potential with retinal illumination is dependent on the metabolic efficiency of the retina and any deficiency reduces the ratio to a subnormal value.

More details of the theory, technique, and clinical application of the test are published elsewhere (Arden and Kelsey, 1962; Arden, Barrada and Kelsey, 1962).

\section{Electroretinography (ERG)}

A Karpe scleral lens or a modified Burian-Allen contact lens was used. The light source consisted of a tungsten filament lamp in a modified box camera with constant aperture and shutter speed. An effective stimulus of intense scattered light (3 LU above threshold) was directed into the eye. Neutral density filters were employed to alter the light intensity as required for photopic or scotopic conditions. The highest intensity of light produced a single flash ERG with a large $a$ wave and sharp $b$ wave. An alternative light source was a Karpe lamp fed by a condenser discharge mechanism, which was used for the ERG in Case 1.

\section{Case Reports}

Case 1, a woman aged 62 years, was first seen at Moorfields Eye Hospital in 1961, complaining of attacks of headache and blurred left vision. She was found to be having subacute attacks of glaucoma in the left eye and pigmentation of the left fundus was noted. The patient had seen an eye specialist 10 years previously on account of headaches and at that time a great interest was taken in the fundus but no notes of this are available.

The family history and general examination showed nothing significant.

\section{Examination of the Eyes}

Right Eye: Visual acuity 6/6; anterior segment normal; fundus normal.

Left Eye: Visual acuity 6/12; anterior chamber shallow, no flare or cells. Gonioscopy narrow but open angle. Pupil miosed with pilocarpine. Vitreous clear. Fundus scattered "bone corpuscle"-shaped patches of pigment over much of the fundus, with pigment sheathing of the veins; disc slightly pale; vessels within normal limits.

Visual Fields (Fig. 1, opposite) : Right eye normal. Left eye "tunnel" vision with small remaining patch of vision at nasal periphery.

Dark Adaptation (Fig. 1): Both eyes within normal limit.

EOG and ERG (Fig. 1): The EOG results can be seen in Fig. 1. The right eye gave a normal response to light, while the left eye remained unchanged. The right ERG was normal, but the left showed a minimal response to the highest intensity of light flash. Possibly a slightly larger response could have been recorded if the pupil had not been constricted with pilocarpine.

Colour Vision: No abnormality in either eye. 


\section{ELECTRO-OCULOGRAM}
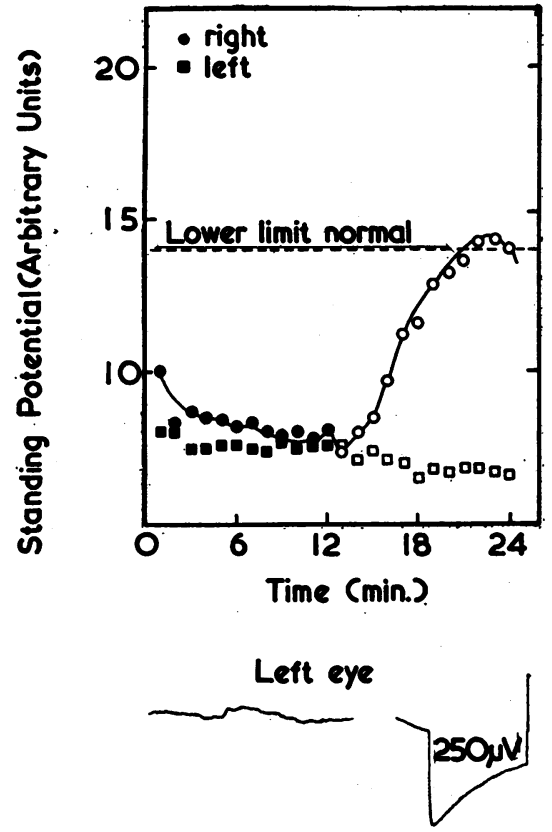

VISUAL FIELDS

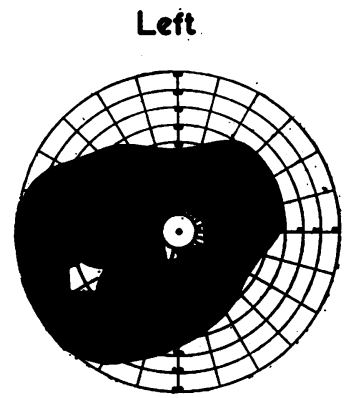

Right

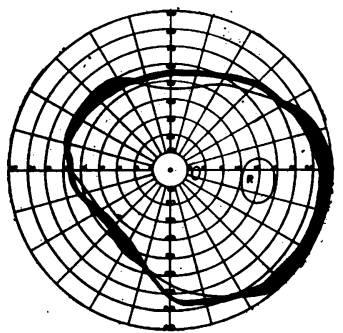

ELECTRORETINOGRAM

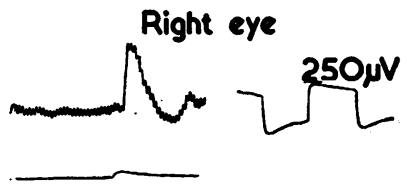

DARK ADAPTATION THRESHOLD

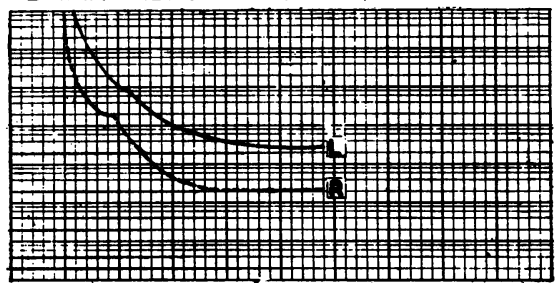

Fig. 1.-Case 1.

Electro-oculogram: right eye circles, left eye squares: black in dark, open in light.

The left eye is unaffected by light after $12 \mathrm{~min}$.

Electroretinogram: right normal, left minute.

Calibration: $250 \mu \mathrm{V}, 250 \mathrm{msec}$. right; and $250 \mu \mathrm{V}, 575 \mathrm{msec}$. left.

Visual Fields: dense defect in left eye.

Dark adaptation threshold: slightly raised in left eye.

Case 2, a woman aged 50 years, was first seen at Moorfields in 1951, with a left infected chalazion. At this date the visual acuity was 6/9 in the right eye, and 6/24 in the left. Pigmentation of the left fundus was noted.

The family history and general examination showed nothing significant.

\section{Examination of the Eyes}

Right Eye: Visual acuity 6/9; anterior chamber clear; lens clear; vitreous two small floaters; fundus disc normal, macula normal, no pigmentation.

Left Eye: Visual acuity hand movements; anterior chamber clear; lens clear; vitreous detachment; fundus pale disc, arteries attenuated, pigmentation of bone spicule type and in irregular 
patterns throughout the posterior pole extending to the equator, some arranged about blood vessels (Fig. 2).

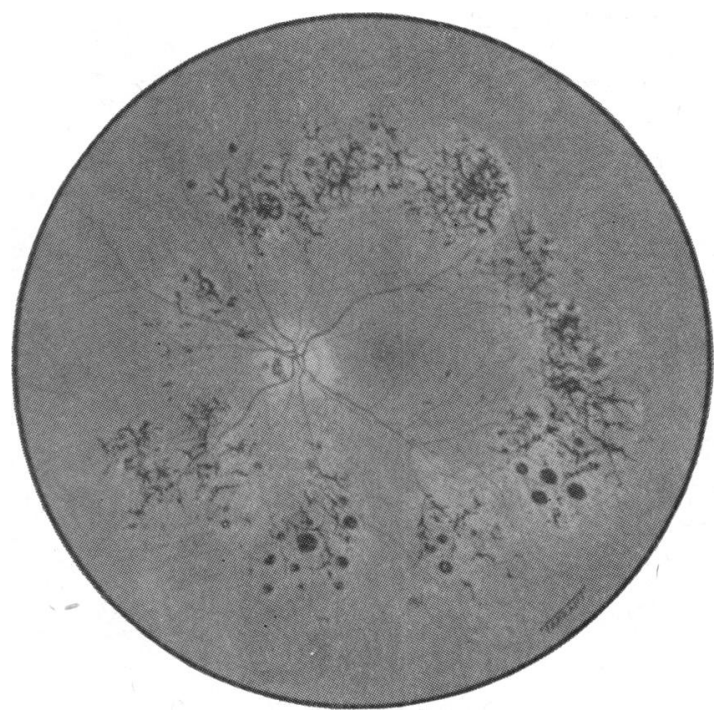

Fig. 2.-Case 2. Left fundus.

Visual Fields (Fig. 3, opposite): Right eye normal. Left eye dense defect, sparing much of inferior temporal quadrant but including fixation.

Dark Adaptation: Right eye normal. Left eye essentially normal threshold but no rod cone break. This is probably insignificant.

EOG and ERG (Fig. 3): In the right eye, the EOG was slightly subnormal and in the left it showed no response to light. Electroretinography in the right eye was normal. A ' $b$ ' wave of 600 microvolts could be evoked by the highest intensity with ' $a_{1}$ ', ' $a_{2}$ ', ' $x$ ', and ' $b$ ' waves. The ERG of the left eye showed only a small negative deflection at the highest light intensity.

Colour Vision: Right eye normal. Left eye no perception of colour.

Case 3, a woman aged 67 years, presented with deteriorating vision. The right eye had been found to have poor vision by an optician 4 years previously. Apart from this, she had no previous history of eye disease or injury.

Family History: There was no history of blindness, poor vision, or associated defects.

General Examination: Nil significant. Blood pressure 160/80; Wassermann reaction negative; erythrocyte sedimentation rate and blood picture normal.

\section{Examination of the Eyes}

Right Eye: Visual acuity hand movements; right divergent squint; pupil no direct reaction to light but normal consensual reaction; anterior chamber clear; lens cuneiform and marked posterior cortical lens opacities; vitreous clear; fundus atrophic disc with attenuated vessels, scattered patches of pigment overlying the vessels more dense in upper nasal quadrant, macular area clear of pigment. The pigment occurred in clumps rather than in the typical "bone corpuscle" formation.

Left Eye: Visual acuity 6/9; pupil reacts directly to light but not consensually; anterior chamber clear; lens cuneiform lens opacities with minimal posterior cortical changes; vitreous clear; fundus disc normal, no pigmentation, slight vascular arteriosclerotic changes. 
ELECTRO-OCULOGRAM

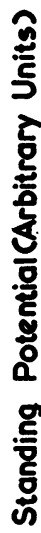

L.U.

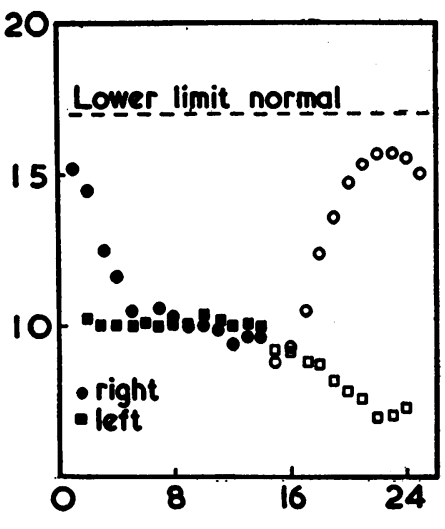

Time (min.)

\section{ELECTRORETINOGRAM}

VISUAL FIELDS
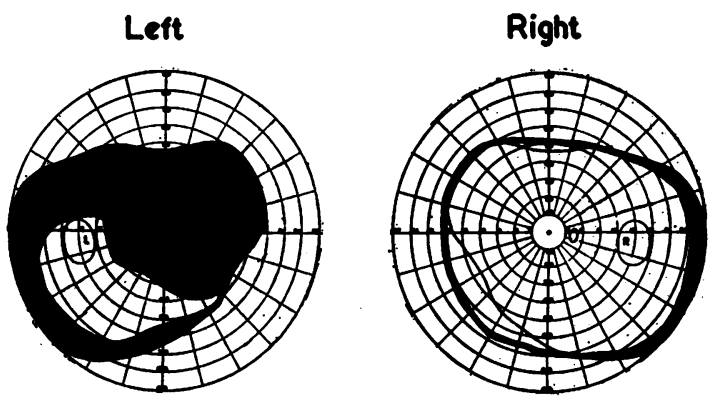

Right eye

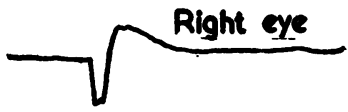

I L. U.
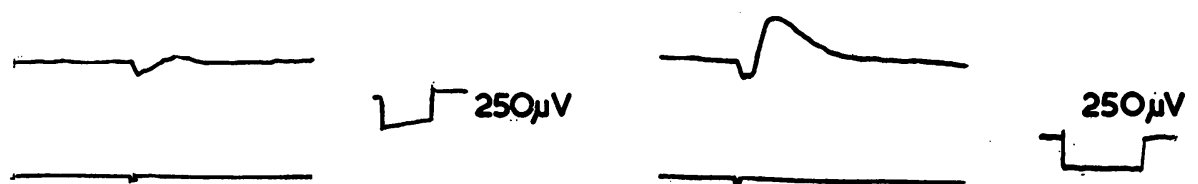

Fig. 3.-Case 2.

Electro-oculogram: no response to light in left eye after $15 \mathrm{~min}$.

Electroretinogram: OLU photopic, ILU scotopic.

Calibration: $250 \mu \mathrm{V}, 200 \mathrm{msec}$. right; $250 \mu \mathrm{V}, 250 \mathrm{msec}$. left.

Visual Fields: defect in left eye.

Visual Fields (Fig. 4, overleaf): Right only a small area remaining inferiorly to $1^{\circ}$ white target. Left eye no abnormality.

Dark Adaptation: Inconclusive results because the patient was a poor witness.

EOG and ERG (Fig. 4): The EOG of the right eye is unaffected by light whereas that of the left eye shows an increase in potential which is still, however, slightly subnormal. Both photopic and scotopic ERG responses of the left eye are normal. In the right eye only reduced scotopic and photopic ERGs (100 microvolts) could be evoked.

Colour Vision: The Ishihara charts could be read normally by the left eye but were not seen at all by the right.

\section{Criteria for Diagnosis}

\section{Comments}

(a) The affected eye must demonstrate the features of retinitis pigmentosa.

(b) The other eye must be unaffected by possible associated disease. 
ELECTRO-OCULOGRAM

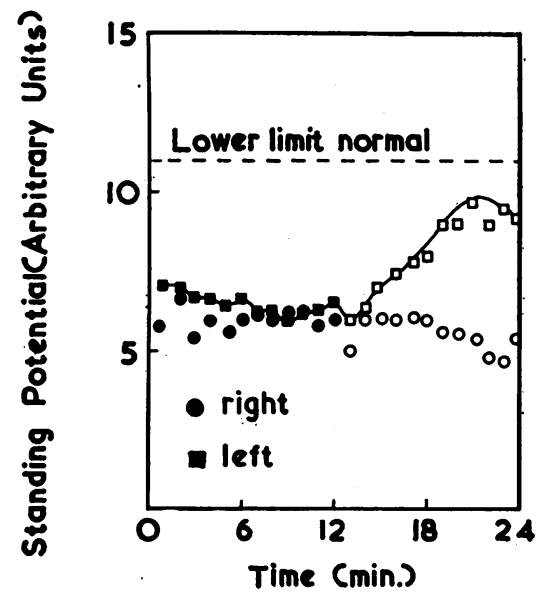

VSUAL FIELDS

Left
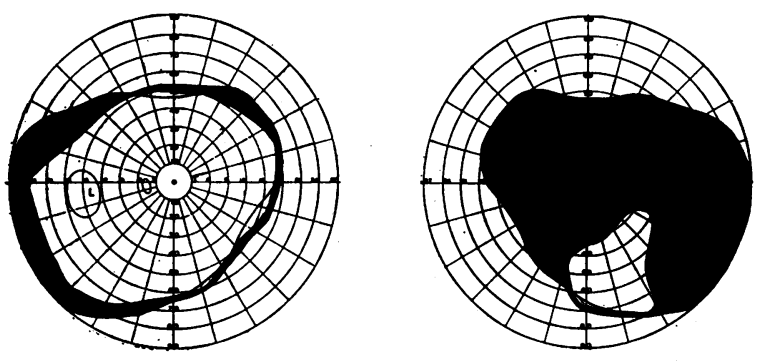

ELECTRORETINOGRAM.

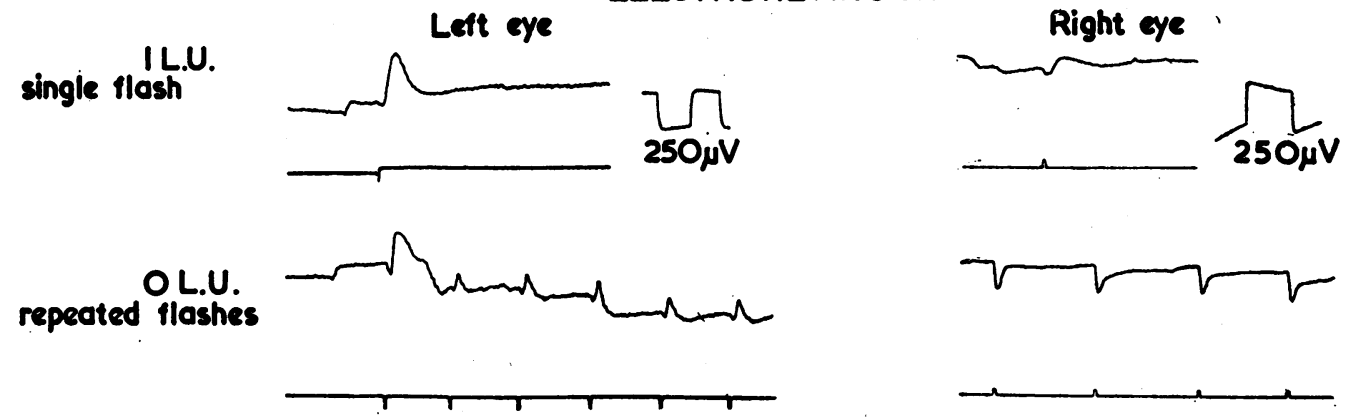

Fig. 4.-Case 3.

Electro-oculogram: no response to light in right eye after $12 \mathrm{~min}$.

Electroretinogram: OLU photopic, ILU scotopic single flash.

Right eye gives a small negative photopic response and a minute positive response to a scoptopic light flash.

Calibration: $250 \mu \mathrm{V}, 125 \mathrm{msec}$. left; $250 \mu \mathrm{V}, 200 \mathrm{msec}$. right.

Visual Fields: dense defect in right eye.

Case 3 had a senile cataract in the unaffected eye and in Case 2 there were some vitreous floaters. In no case was there any pigmentation.

(c) Observation for long enough to exclude bilateral involvement.

Case 2 had been noted to have a pigmented fundus 12 years previously. Case 3 had been noted to have poor vision in one eye 4 years previously. The age of all these cases, i.e. all over 50 years, also excludes the likelihood of the other eye becoming involved.

(d) Exclusion of history of injury or possible associated systemic disease.

Mann (1957) recorded a case of unilateral pigmentation of the fundus associated with a forceps injury to the left eye at birth. Rubella, syphilis, and tuberculosis are all known to cause fundal pigmentation though this is normally bilateral. It is also 
possible that localized vascular disease, perhaps occurring years previously, could produce the same effect.

A detailed history was taken and general medical examination performed in an attempt to rule out some of these other possible causes. This included chest $x$ ray, Wasserman reaction, and Kahn tests as well as erythrocyte sedimentation rate, and a full blood count. No significant abnormality was found in any of the three cases.

\section{Electrodiagnostic Tests}

Electroretinography.-In all three cases the ERG from the unaffected eye was quite normal in waveform, amplitude, and relationship to light intensity. The increase in size of the $b$-wave with dark adaptation was quite normal and there was, therefore, no indication of loss of rod sensitivity.

In the affected eye of all three cases some ERG could be recorded. In Case 2 and Case 3 single flashes of high intensity light (4 LU above threshold) evoked a negative ERG. Possibly this is the 'receptor' potential as described recently by Brown and Watanabe (1962). A small $b$-wave was recordable in Case 3, but showed no change of amplitude with dark adaptation. In Case 2 it is doubtful whether any $b$-wave was present at all and in Case 1 only a minute electropositive deflection could be evoked by the highest intensity (4 LU above threshold).

It is interesting to note that the most pathological ERG was from the case with the greatest field loss (Case 1) and where larger but negative ERGs could be evoked a substantial part of the peripheral field was still functioning.

However, it has not always been found easy to correlate the amplitude of the ERG with other clinical tests such as the visual fields (Arden and Fojas, 1962). It has been found possible to evoke ERGs with high intensity stimuli where there is severe field loss, and on the other hand no ERG is recordable in many cases of less severe field losses. By the new techniques involving computor analysis of ERGs it has now been possible to record ERGs where stimulus and recording conditions were previously inadequate to evoke a response (Armington, Gouras, Tepas, and Gunkel, 1961).

The discrepancies in ERG recordings from different cases of retinitis pigmentosa may indicate the occurrence of two separate diseases, both presenting the same clinical picture but affecting different parts of the retina. One type of disease in which there is no recordable ERG might be due to a lesion in the rods; in the other type, the lesion may be primarily in the pigment epithelium and enough rods may be functioning to allow "receptor" ERGs to be recorded.

Electro-oculography.-The rise in corneo-fundal potential after prolonged exposure to light is thought to be related to the synthesis of visual purple, and intact pigment epithelium and rods are thus necessary for the normal response. In no case of retinitis pigmentosa studied by the EOG (Arden and Fojas, 1962), could a light rise be induced, even when the visual fields, dark adaptation, and ERGs were only slightly affected. This is evidence of the sensitivity of the test in cases of pigmentary degeneration.

In the cases discussed here, the EOG is "flat" in the diseased eye but shows a definite light rise in the unaffected eye. This is evidence that the affected eye has a completely degenerated pigment epithelium, similar to that of an eye with retinitis 
pigmentosa. In all three cases the EOG of the affected eye shows a slight fall rather than a rise on light adaptation, indicating that the recordable potential is completely unaffected by light and the reversal of sign is the result of "cross-talk" between the recording electrodes.

An interesting finding is that the "good eye" in all three cases gives a slightly lower than normal light rise. This may indicate that, despite the usual tests showing the eye to be quite normal, a metabolic deficiency is present in the pigment epithelium of the 'good' eye although not to the extent of the diseased eye.

Dark Adaptation.-The dark-adaptation curves in our three cases were not strikingly pathological. The threshold was near normal, indicating little loss of rod sensitivity. In Cases 2 and 3 a considerable amount of retina is functioning, as shown by perimetry, but in Case 1 the minute field retained would indicate almost complete loss of rod function if this were the classical type of retinitis pigmentosa. The fact that in all three the dark adaptation was practically normal is also evidence that this disease is not a degeneration of the rods alone.

Heredity.-In keeping with the previously reported cases there is no significant family history in our three cases. The discovery of a recognized associated defect (for example, deafness or mental deficiency) either in the subjects themselves or in their relatives would have been suggestive of the hereditary form of the disease. The case with unilateral closed-angle glaucoma is interesting because a relationship between both closed and open-angle glaucoma and bilateral retinitis pigmentosa has been noted in the past (Gartner and Schlossman, 1949). Case 3 had a complicated cataract on the affected side, but it is thought that cataract is not governed by an associated genetic factor in the bilateral disease, although this has been proved to be so in animals. The inheritance of a unilateral defect is quite feasible as instanced by heterochromia iridis or cleft lip and palate.

\section{Discussion}

Unilateral retinitis pigmentosa is coming to be recognized as a true condition, but it also appears that it is probably distinct from the bilateral form. This is suggested by the absence of any family history in almost all the cases reported and by the late onset. There is no evidence as yet that it is a partial manifestation of the hereditary form, and many of the cases previously reported were probably of secondary origin. No causal factor could be shown in the three cases described. However, the nature of the electrodiagnostic findings suggest that this disease is of a different nature from the classical hereditary retinitis pigmentosa and that it is possibly a partial manifestation of a bilateral disease.

Although clinically the affected eye appears typical of the hereditary retinitis pigmentosa, the electrophysiological tests indicate a significant difference. ERGs are present and similar to the 'receptor' potentials of Brown and Watanabe (1962), even where visual field loss is almost total. Dark adaptation is near normal, which does not indicate much loss of rod sensitivity. Such findings have been reported in some cases of the bilateral disease (Arden and Fojas, 1962) and suggest that the universally accepted retinitis pigmentosa can be of two types-the one affecting primarily the rods, of hereditary nature, and the other affecting primarily the pigment 
epithelium or associated membranes, causing membrane potential upsets and eventually pigmentary degeneration indistinguishable clinically from the first type.

The subnormal EOGs in all three cases suggest that the 'good' eye is slightly affected but not to the extent of the obviously pigmented and degenerated fundus of the diseased eye. The condition appears to be stationary as indicated by the previous ocular history.

In conclusion we can state that the three cases presented here show clear evidence of a pigmentary retinal degeneration in the one eye similar to the condition described as "unilateral retinitis pigmentosa" but with implications that the other eye is partially affected. It is also suggested that this is a disease primarily of the pigment epithelium and thus distinct from the hereditary bilateral form.

\section{Summary}

Three cases of unilateral retinal pigmentary degeneration are described and discussed in relationship to bilateral retinitis pigmentosa with particular emphasis on the results of the electrodiagnostic tests.

We are indebted to Dr. A. MacDonald for performing general medical examinations and to Dr. G. B. Arden for helpful discussions.

\section{REFERENCES}

Agatson, S. A. (1939). Amer. J. Ophthal., 22, 420.

Arden, G. B., and Barrada, A. (1962). Brit. J. Ophthal., 46, 468.

$\longrightarrow,-$, and KELSEY, J. H. (1962). Ibid., 46, 449. and KelseY, J. H. (1962). J. Physiol. (Lond.), 161, 189; 205.

and Fojas, M. R. (1962). Arch. Ophthal., 68, 369.

Armington, J. C., Gouras, P., Tepas, D. I., and Gunkel, R. (1961). Exp. Eye Res., 1, 74.

Baumeister, E. (1873). v. Graefes Arch. Ophthal., 19, pt 2, p. 261.

Beigelman, M. N. (1931). Arch. Ophthal. (Chicago), 6, 254.

Brown, K. T., and WATANABE, K. (1962). Nature (Lond.), 193, 958.

DeRIGS, G. (1882). " "Ueber Retinitis Pigmentosa." Inaugural Dissertation, Bonn.

Dieterle, P., and Avanza, C. (1960). Atti XLIV Cong. Soc. oftal. ital., 18, 267.

Dreisler, K. K. (1948). Acta ophthal. (Kbh.), 26, 385.

FrançoIs, J., and VerRIEST, G. (1952). Ophthalmologica (Basel), 134, 65.

FrohmanN, C. (1957). Klin. Mbl. Augenheilk., 130, 102.

Fronimopoulos, J., Cofinas, H., and Lambrou, N. (1960). Bull. Hellen. Soc. Ophthal., $28,67$.

Gartner, S., and Schlossman, A. (1949). Amer. J. Ophthal., 32, 1337.

GüNSBURG, F. (1890). Arch. Augenheilk., 21, 184.

Hine, M. L. (1924). Proc. roy. Soc. Med., 17, Sect. Ophthal., p. 14.

KrILL, A., and IsER, G. (1959). A.M.A. Arch. Ophthal., 61, 626.

KüPer, J., Mülller-Limroth, W., and Dieckhues, B. (1962). Klin. Mbl. Augenheilk., $41,697$.

LEBER, T. (1915-1916). "Die Krankheiten der Netzhaut". In "Graefe-Saemisch-Hess Handbuch der gesamten Augenheilkunde," 2nd ed., band 7a, teil 2, Kap. 10A. Engelmann, Leipzig.

Maeder, G., and Müller, P. (1950). Ann. Oculist. (Paris), 183, 771.

MANN, I. (1957). "Developmental Abnormalities of the Eye”, 2nd ed., p. 141. B.M.A., London.

MehlmaCK, F. (1961). Wiss. Z. Univ. Leipzig, Math.-nat. Reihe, 10, 750.

MEHRA, K. S. (1962). Brit. J. Ophthal., 46, 310.

NeTtleship, E. (1907). Roy. Lond. ophthal. Hosp. Rep., 17, 1.

Pedraglia, (1865). Klin. Mbl. Augenheilk., 3, 114.

RossI, D. (1926). Boll. Oculist., 5, 363.

SHOJ, Y. (1926). Arch. Ophtal. (Paris), 43, 402.

WECKER, L. de (1870). "Traité théorique et pratique des maladies des yeux", vol. 2, p. 337 . Delahaye, Paris. 